\title{
Polícia, PCC e dispositivo letal em São Paulo
}

\author{
Gabriel de Sousa Romero ${ }^{12}$ \\ Recebido em novembro de 2019 \\ Aceito em dezembro de 2019
}

\section{RESUMO}

No contexto democrático brasileiro contemporâneo, a equação entre eficiência policial e amplo respeito aos direitos civis resulta num paradoxo: o uso continuamente abusivo, excessivo e seletivo da força pelas polícias, contribui decisivamente à manutenção de índices elevados de homicídios dolosos. Além dos altos índices de letalidade policial verificados nas últimas décadas, a orientação punitivista das políticas de controle do crime são atestadas também pelo cenário de encarceramento em massa, que expõem os detentos a situações degradantes de aprisionamento. Inserido neste contexto, a emergência do Primeiro Comando da Capital (PCC) no início da década de 1990 e sua atuação nas prisões paulistas e em comunidades periféricas, é decisiva para compreender a regulação do uso da força pelo Estado e a influência da organização criminal na gestão dos conflitos violentos do "mundo do crime". Diante dessa conjuntura, a pesquisa buscou problematizar o uso da força pelas agências policiais e o pelo PCC em São Paulo, a fim de discutir a tendência de militarização das forças policiais, bem como as implicações das relações entre agências estatais e criminais na determinação de políticas de segurança.

Palavras-chave: Segurança Pública; Letalidade Policial; PCC

\begin{abstract}
In the contemporary brazilian democratic context, the equation between police efficiency and broad respect for civil rights results in a paradox: the continually abusive, excessive and selective use of force by police, contributes decisively to the maintenance of high rates of willful murder. In addition to the high rates of police lethality observed in recent decades, the punitive orientation of crime control polices is also attested by the scenario of mass incarceration, which exposes detainees to degrading situations of imprisonment. Inserted in this context, the emergence of the Primeiro Comando da Capital (PCC) in the early 1990 and its performance in São Paulo prisons and peripheral communities is crucial to understand the regulation os the use of force by the state and the influence of criminal organization in management of violent conflicts in the "word of crime". Given this conjuncture, the research sought to problematize the use of force by police agencies and the PCC in São Paulo, in order to discuss the tendency of militarization of police forces, as well as the implications os relations between state and criminal agencies in determining security policy.
\end{abstract}

Keywords: Public Security; Police Lethality; PCC

\section{RESUMEN}

En el contexto democrático brasileño contemporáneo, la ecuación entre la eficiencia policial y el amplio respeto por los derechos civiles resulta en una paradoja: el uso continuo, abusivo, excesivo y selectivo de la fuerza por parte de la policía contribuye decisivamente al mantenimiento de altas tasas de asesinatos deliberados. Además de las altas tasas de letalidad policial observadas en las últimas décadas, la

1 Pós-Graduando no Programa de Pós-Graduação em Ciências Sociais da Universidade Federal de São Paulo (UNIFESP), pesquisador do Observatório de Segurança Pública (OSP). Contato: emaildoromero@gmail.com.

2 Uma primeira versão deste texto foi apresentada na $\mathrm{X}$ edição do Seminário Nacional Sociologia \& Política da Universidade Federal do Paraná, em 2019. 
orientación punitiva de las políticas de control del delito también está atestiguada por el escenario de encarcelamiento masivo, que expone a los detenidos a situaciones degradantes de encarcelamiento. Insertado en este contexto, el surgimiento del Primer Comando de la Capital (PCC) a principios de la década de 1990 y su desempeño en las cárceles y comunidades periféricas de São Paulo es crucial para comprender la regulación del uso de la fuerza por parte del estado y la influencia de la organización criminal en gestión de conflictos violentos en el "mundo del crimen". Dada esta coyuntura, la investigación buscó problematizar el uso de la fuerza por parte de las agencias policiales y el PCC en São Paulo, a fin de discutir la tendencia de la militarización de las fuerzas policiales, así como las implicaciones de las relaciones entre el estado y las agencias criminales para determinar la política. de seguridad.

Palabras Clave: Seguridad Publica; Letalidad Policial; PCC

\section{Controle social e monopólio legal da força: aprofundando a análise contemporânea da segurança pública paulista}

A

manutenção de estratégias militarizadas e letais pelas agências policiais, bem como

a expansiva consolidação de vínculos políticos, econômicos e morais oriundas do chamado "mundo do crime" (FELTRAN, 2008), constituem dois dos principais e atuais temas de pesquisa da sociologia da violência. Além das características e diferentes formas que agenciam o uso da força, e da decisiva intervenção nos múltiplos fenômenos da "violência urbana", as interferências desses dois atores no problema da redução do número de homicídios em São Paulo é um campo de pesquisa aberto.

Esta comunicação tem como objetivo, portanto, debater o contexto contemporâneo de violência letal em São Paulo a partir do desenvolvimento de uma questão principal: como organizações estatais e não-estatais, especificamente as forças policiais paulistas e o Primeiro Comando da Capital (PCC), regulam um dispositivo letal através de mecanismos e estratégias que buscam legitimar o uso centralizado da força que operam?

Diante dessa complexa questão, a etapa inicial de pesquisa tratou de resgatar as principais discussões e o contexto político-social da formação do "campo da segurança pública" do Brasil (VASCONCELOS, 2017). Esse processo, que decorreu nas últimas décadas do século XX, é marcado por uma institucionalização da análise sociológica do sistema de segurança e justiça, e dos múltiplos fenômenos da chamada "criminalidade urbana violenta" (ADORNO, 1993). 
Num primeiro momento, as atenções dos pesquisadores e pesquisadoras estavam voltadas, sobretudo, às violações dos direitos humanos (tortura, assassinato e ocultação de cadáveres, por exemplo) praticadas pelo Estado durante o regime militar (1964-1985). Já no início dos anos 1990, sob a égide de uma Constituição Federal, a resistência das polícias às reformas democráticas foi um dos principais elementos destacados e atestado no campo acadêmico, vide a manutenção de padrões de ação policial violenta, por elevados e constantes níveis de letalidade, pelas evidências da atuação de policiais em grupos de extermínio e na participação dos agentes em chacinas (NEME, 1999).

Num Estado democrático de Direito, o uso legal da força pela polícia refere-se a um dispositivo de controle que prevê como conduta adequada o respeito à proporcionalidade, ou seja, que o recurso da arma de fogo seja utilizado respeitando uma escala de intervenção e apenas em último caso. No entanto, a "letalidade policial" (SOUZA, 2015) constitui um grave e complexo problema do Brasil contemporâneo, já que está ligada a uma rede de relações de poder e de saberes (FOUCAULT, XXXX), jurídicos e policiais, que reproduzem através do discurso de combate ao "criminoso" práticas letais seletivas.

Outro movimento histórico recente importante para compreender o contexto atual é o desenvolvimento do sistema penitenciário paulista. Além de um alto índice de mortos pela polícia, há desde 1980 um avolumamento significativo da população carcerária no Brasil, em geral. E foi dentro dos presídios que não só nasceram as chamadas "facções criminosas", como também é aí um importante território utilizado para fortalecer os vínculos político e econômicos entre os grupos criminais.

Um conceito importante para tratar esse conjunto de problemas é a noção de “controle social”. Atrelada à tradição durkheimiana de investigação dos mecanismos de solidariedade social e de caracterização da "anomia", ou seja, dos problemas que constituem o desvio à manutenção da ordem (DURKHEIM, 2010), já no século XX a noção é retomada no contexto da sociologia norte-americana, que ao invés de procurar os princípios de coesão social através do Estado, tratou-os numa perspectiva microssociológica (ALVAREZ, 2004). 
No contexto pós $2^{\underline{a}}$ Guerra Mundial foi formulado um novo conjunto de questões sobre as relações sociais, reorientando o "controle social" de sua acepção clássica como princípio de integração social e como estrutura centralizada de poder, valorizando num sentido positivo a construção da própria realidade a partir da micromecânica dos dispositivos disciplinares e biopolíticos (FOUCAULT, 1988).

Neste campo analítico se destacam as formulações do filósofo Michel Foucault, sobretudo a respeito da formação de um dispositivo penal, vigilante e interventor nas subjetividades e na coletividade populacional, no Ocidente moderno (FOUCAULT, 2008; 2014). Para Foucault (2014) a fórmula da prisão possibilitou não só um agenciamento disciplinar, mas permitiu a manutenção de determinadas relações de poder hierárquicas e de dominação, através das quais se realiza uma gestão diferencial dos ilegalismos e se reproduz a delinquência, como próprias ferramentas de governo.

Foucault $(1988 ; 2014)$ estabelece uma nova metodologia de análise das relações sociais, a arqueo-genealogia, através da qual podemos identificar e interpretar a configuração das tecnologias de poder e dos processos de sujeição que permitem o gerenciamento da vida e a regulação da morte na sociedade moderna (o que caracteriza o regime biopolítico). O conceito de "poder" na acepção foucaultiana não remete a uma intensificação do "controle social", assim como não possui um significado meramente proibitivo e repressivo. Dotado de um caráter positivo, ele se refere às próprias relações sociais, às relações de força que se exercem em diferentes níveis e com extensões variadas (FOUCAULT, 2010).

Para Foucault (1988), o regime de biopoder se encarrega, portanto, de potencializar a vida da população, dos indivíduos em conjunto, através de saberes sobre o governo da vida, dentre os quais não estão descartadas políticas de morte (FOUCAULT, 2010). A partir da máxima soberana do regime de biopoder, "fazer viver, deixar morrer" (FOUCAULT, 1988, p.150), podemos nos questionar através de quais meios se "deixa morrer" e quais vidas são entregues à morte.

Neste sentido, o "controle social” não deve ser concebido como uma categoria analítica fechada, e sim como ferramenta de interpretação de determinado arranjo de práticas de poder. Numa análise local, podemos caracterizar os processos contemporâneos de restrição de direitos e de instalação de dispositivos de exceção no 
interior dos procedimentos formais do ordenamento jurídico, como mecanismos de regulação, controle e produção de comportamentos compatíveis a uma lógica punitiva e letal de segurança.

Considerando não haver pena de morte no Código Penal Brasileiro, o princípio de "manutenção da ordem" que rege o uso legal da força e os altos índices de homicídio dolosos praticados pela polícia, é possível afirmar, portanto, que na experiência urbana atual estão borradas as fronteiras entre legalidade/ilegalidade, formalidade/informalidade (TELLES, 2010).

Outro conceito fundamental e muito influente nas discussões sobre segurança pública no Brasil é o "monopólio da força” (WEBER, 2003). No pensamento sociológico weberiano o Estado constitui-se como legitimo detentor do poder de usar a força na mediação das relações sociais. Evidentemente há limites de exercício da força e da coação física a serem respeitados, que se identificam com a própria formação do Estado e o alcance de sua legitimidade, constituindo-se "na única fonte do 'direito' à violência” (WEBER, 2003, p.56). A pacificação e modernização da sociedade Ocidental, engendrados através de outros processos como o "desencantamento do mundo" e a burocratização da máquina estatal, são marcados por uma ação voluntária dos cidadãos que entregam seu "poder" ao Estado. Essa relação é sustentada através de três possibilidades de sujeição: tradicional, carismática e legal (WEBER, 2003). Nesta última, a obediência é em relação a um código estabelecido, a um estatuto, que denota a autoridade característica do Estado moderno.

Adorno (2002), ao retomar a questão weberiana do monopólio estatal da violência numa interpretação sobre o Estado brasileiro, identifica a erosão desse monopólio como resultado de um parcial processo de modernização nacional, caracterizado pela privatização do uso da força (pelos próprios agentes policiais e por empresas de segurança privada), pela presença armada do crime organizado e, também, pela centralidade da violência na resolução dos conflitos interpessoais. Há, neste sentido, uma indiferenciação do monopólio da violência e um apagamento do marco civil democrático.

Comparados internacionalmente os casos de violência policial indicam as polícias brasileiras como uma das mais letais do mundo (FÓRUM, 2016). Há de fato 
uma disjunção entre um Estado de Direito e o modelo de segurança nacional (CALDEIRA, 200o), que apesar de não se encontrar declaradamente em uma "guerra", preconiza o caráter bélico do combate ao "crime" e às "drogas". Apesar das diferentes prerrogativas de autorização do uso da força pela Polícia - segurança interna - e pelas Forças Armadas (FA) - segurança externa -, há um processo crescente de militarização das polícias e a policialização das FA (SOUZA, 2015). A este cenário se soma uma estratégia de gestão dos riscos, controle e eliminação dos "perigos sociais" que permite a gestão de ilegalidades e a marginalização dos indesejáveis (TELLES, 2010).

Segundo Vera Telles (2010), no Brasil da redemocratização houve um deslocamento das questões sobre os direitos e sobre a modernização incompleta, que requerem uma atualização dos referenciais a partir dos quais se formulam as questões sobre segurança e violência. Daí a necessidade e a relevância de buscar outros referenciais para acompanhar os fluxos estabelecidos nas dobras, nas fronteiras do legal/ilegal, onde se disputam legitimidades e se desenrolam os conflitos (TELLES, 2010).

Resumindo o problema da violência policial contemporânea, podemos perceber a articulação de complexas tramas políticas, negociações, projetos de reforma dos dispositivos de segurança pública, de incentivo às políticas penais, ao encarceramento, à letalidade policial, entrecortadas por relações de poder autoritárias e hierarquizantes que associam certas categorias de "suspeitos" e "bandidos" como alvos preferenciais do dispositivo penal. Por outro lado, conforme abordaremos adiante, indagando as tramas ilegais e a organização do "mundo do crime" têm-se acompanhado nos últimos 20 anos o crescimento de uma organização criminosa que consolidou uma extensa estrutura política e econômica (informal) dentro do estado de São Paulo, e que atualmente disputa o controle de outros territórios, nacionais e internacionais, impactando ai também, por exemplo, no problema e nas dinâmicas do conflito violento (DIAS \& MANSO, 2018).

Trata-se, portanto, de indagar o problema da guerra na sociedade civil (FOUCUALT, 2010) recolocando o "controle social" e o "uso legal da força” em outros patamares teóricos. A análise das práticas de segurança pública permite afirmar que a militarização da segurança pública corresponde à possibilidade de assassinar os 
indivíduos "perigosos", os "bandidos", e, portanto, os potencialmente matáveis (AGAMBEN, 2004; FOUCUALT, 2010). E, também que o processo de consolidação do PCC, a disciplina posta como norma e os ideais de "igualdade" propagados pela organização no "mundo do crime", correspondem a um específico processo ancorado em discursos de "pacificação social", cuja principal prerrogativa é justamente a centralização do uso da força (DIAS, 2014) e seu consequente uso na manutenção de estruturas de poder informais e autoritárias.

As redes de poder e os fluxos dos mecanismos de regulação social são tema de interesse social que não estão restritos ao ambiente acadêmico. $\mathrm{O}$ estudo da segurança pública, das formas de administração dos conflitos urbanos, dos mecanismos punitivos contemporâneos e das possibilidades pelas quais se produz a morte, têm ligação direta com o aprofundamento dos debates sobre a manifestação das desigualdades sociais, raciais, de gênero e etárias, que expõem populações marginalizadas às múltiplas formas de controle disciplinar e violência (SINHORETTO, et. al., 2004).

\section{Consolidação e hegemonia do PCC}

Nas áreas urbanas os discursos sobre segurança remetem, de modo geral, ao universo dos eventos que envolvem a experiência do "crime" e que permitem equacionar uma série de previsões sobre os riscos da vida moderna, interferindo diretamente na manutenção da ordem pública. Neste sentido, a pesquisadora Teresa Caldeira (200o) identificou como um sentimento de insegurança impulsionado por uma série de fatores sociais, econômicos e políticos, interferiu diretamente na organização socioespacial paulistana e alterou substancialmente a gestão do uso da força pelo Estado.

A partir de dados reunidos durante as décadas de 80 e 90 - como aumento do número de crimes violentos (principalmente roubo e tráfico), densidade demográfica (somada aos problemas urbanos daí decorrentes) e ainda a transição democrática no final do século XX -, Caldeira (200o) percebeu que mesmo com o fim de um governo militar e a abertura da experiência democrática, houve a acentuação de uma segregação social espetacular. A necessidade de "proteção" desencadeada pela 
retomada do "criminoso" (estereótipo associado ao "marginal", ao "ladrão" e ao "traficante") como principal inimigo social, ampliou o espectro de ações ilegais dos agentes policiais, o mercado de segurança privada e a construção de "enclaves fortificados"; aliando o desrespeito aos direitos democráticos, como a cidadania, a uma normatividade violenta de combate ao "crime".

Num contexto de experiência da vida moderna marcada por um individualismo crescente, a segurança pública parecer ser o campo que integra complexas redes pessoais e técnicas, baseadas na vigilância disciplinar contínua e em estratégias militares de defesa social, como o ataque e a eliminação do "oponente". Nessas condições, analisar o uso da força e a violência nas relações entre policiais e não-policiais não é uma tarefa fácil. Mesmo o restrito fenômeno das mortes resultantes dos "conflitos" na atuação policial, é composto por diferentes eventos que remetem desde as condições do trabalho dos agentes até uma esfera de atuação paramilitar, vide a atuação de "Esquadrões da Morte" (BUENO, 2014).

Outro aspecto relevante do "combate à criminalidade" tem a ver com o desenvolvimento de um projeto de encarceramento em massa no Brasil. Da década de 1990 até 2016 o número de pessoas saltou de 90 mil para mais de 700 mil (DIAS; MANSO, 2018). Além do mais, as condições de privação de liberdade continuam desumanas, num sistema marcado dentre outros problemas, por um enorme déficit de vagas. Em São Paulo, por exemplo, a formação do PCC em 1993 no Anexo da Casa de Custódia de Taubaté, ocorreu um ano após a truculenta ação policial na Casa de Detenção de São Paulo (Carandiru), que vitimou violentamente 111 pessoas. A gestão dos presídios pelo Estado em condições degradantes e o encarceramento em massa, são apenas alguns dos elementos responsáveis pela formação e pela consolidação do controle político interno do sistema penitenciário pelas facções criminosas.

Atualmente as autoridades públicas e agências de informação estimam a existência de mais de 80 facções criminosas atuando dentro dos presídios (DIAS; MANSO, 2018). Ainda que não se possa precisar o nível de influência de todas essas facções nas dinâmica criminais, é possível afirmar que há um modelo de coalização de criminosos reunidos em torno desses agrupamentos, que apresentam como características gerais: o exercício de um poder centralizado que regula o uso da força, 
aplicação de códigos punitivos a dissidentes e desafetos, e que estabelecem uma rede de influência nas relações sociais dentro e fora das prisões onde atuam. No estado de São Paulo a presença do PCC é hegemônica. Estima-se que a organização controle 9o\% do total de unidades prisionais e seja força política reconhecida em diferentes zonas periféricas (BIONDI, 2014; FELTRAN, 2008; GODOI, 2015).

Em sua tese de doutorado, Camila Nunes (2011) se propôs a fazer um resgate histórico da expansão do PCC no sistema prisional paulista a partir de dois eixos: um horizontal/processual em que se analisa o nascimento e a expansão do PCC, tomando como foco o uso da violência física direta no exercício do poder; e outro vertical/figuracional, que visou investigar os efeitos e compreender as transformações na dinâmica social urbana vigente a luz deste processo. As transformações sociais que desembocaram no surgimento do PCC, bem como a reestruturação da figuração social urbana que o partido do crime continuamente provoca, são percebidas, em geral, pela posição centralizadora das oportunidades de poder que ocupa como referência no cotidiano de diferentes espaços urbanos (DIAS, 2011), em oposição, colaboração e concorrência às normas estatais (BIONDI, 2014; FELTRAN, 2008).

A hipótese é que o PCC articula uma política de segurança própria, decisiva na experiência de insegurança social, o que confere importância singular ao estudo dos processos de estruturação dessa plataforma moral de vigilância e punição. Podemos destacar aqui, duas particularidades desse movimento da organização criminal, fundamentais à interpretação dos conflitos contemporâneos: os processos de legitimação interna através das relações de poder punitivas às transgressões da disciplina do Comando (FELTRAN, 2010), e os processos de legitimação externa, pautados no conflito direto, que caracterizam o atual projeto de expansão (DIAS \& MANSO, 2018).

Quanto à legitimação interna, trata-se de um processo conjuntural oriundo de diferentes transformações ao longo da trajetória da organização. A criação do PCC é fruto de uma ruptura do antigo cenário de pulverização da violência no interior do sistema penitenciário, que expunha os detentos às mais variadas formas de constrangimento físico e moral. A organização desencadeou toda uma rede de interdependência e divisão de funções, que num primeiro momento teve como alvo 
oponentes que não queriam se submeter ao processo de imposição do autocontrole às regras informais do PCC (DIAS, 2011). Esse processo de centralização das oportunidades de poder pautou-se em dois elementos principais: os monopólios econômico e político.

O monopólio econômico diz respeito ao controle dos fluxos econômicos ilegais/informais, bem como o controle das oportunidades de acesso ao bem ilegal (como por exemplo as drogas). O monopólio político, por sua vez, diz respeito ao próprio controle da violência e ao exercício de um rigoroso controle social da população carcerária, que compreende o uso restrito da força no ambiente prisional ao PCC por meio de seus representantes. Conforme indica a bibliografia especializada sobre o tema (BIONDI, 2014; DIAS, 2011; FELTRAN, 2008; MARQUES, 2009) o PCC possui características peculiares que lhe garantiram o exercício de um rígido controle político baseado em ideais de Paz, Justiça, Liberdade e União. Essa narrativa estatutária é constitutiva de processos objetivos de identificação, integração, punição e busca pelo certo daqueles que a compartilham - e estão de algum modo ligados ao mundo do crime.

A expansão desse processo de legitimação interna desencadeou no controle territorial do PCC para além dos muros das instituições prisionais (GODOI, 2015). A este respeito cumpre destacar o processo de "pacificação social" desempenhado pela organização através de dois elementos: a organização de um sofisticado código de condutas e mecanismos de resolução dos conflitos interpessoais através de uma “justiça” paralela. Segundo Camila Dias e Bruno Paes Manso (2018), alguns fatores explicam o fato de ser o PCC a facção brasileira com maior poder de influência. Em São Paulo, a facção conseguiu funcionar como agência reguladora do mercado de drogas, costurando uma ampla rede de parceiros que passou a conviver conforme as novas regras do crime, estabelecidas por salves e estatutos, na qual o homicídio só ocorreria com o aval do grupo.

O PCC tornou-se o grande mediador de conflitos num ambiente antes povoado por pequenos grupos regidos pela lei do mais forte. A pacificação, dessa maneira, agradou ao crime e às autoridades porque reduziu rebeliões e homicídios, ao mesmo tempo que contribuiu para a expansão do faturamento dos criminosos ligados a essa 
rede. A simbiose improvável de interesses foi fundamental para que os paulistas alcançassem esse equilíbrio longevo no mercado de drogas local. (DIAS \& MANSO, 2018).

Um dos mais contundentes e controversos debates sobre o impacto da organização nas dinâmicas sociais paulistas diz respeito ao acionamento da "tese PCC" para explicar a drástica redução dos homicídios em São Paulo entre 1990 e a primeira década dos anos 2000. Uma série de hipóteses foram aventadas para explicar a drástica diminuição no número de assassinatos (como políticas públicas de segurança, campanhas de desarmamento etc.), entretanto, foi decisivo o papel desempenhado pelo Primeiro Comando da Capital (PCC) nas periferias paulistas enquanto instância reguladora dos conflitos (FELTRAN, 2008).

Por enquanto podemos afirmar que, ainda que alicerçado em ideais igualitários o regime disciplinar do PCC é responsável por manter uma estrutura rígida de controle hierárquico, que não é compatível com uma estrutura democrática. No entanto, não há dúvidas a respeito do poder político da organização. Entre os dias 12 e 21 de maio de 2006 por exemplo, uma "crise" na segurança pública paulista revelou a dimensão da força da organização. Segundo alguns estudos, o acontecimento teve origem, dentre outros fatores, com a corrupção policial praticada contra membros do PCC, que desencadeou um desequilíbrio no sistema prisional através de um salve que provocou rebeliões simultâneas nos presídios paulistas.

A situação excedeu o espaço prisional e resultou em ataques dos irmãos a policiais e órgãos das forças da ordem, resultando na morte de 59 agentes. No entanto, a resposta policial ao pânico que se instaurou na cidade foi instantânea, desmedida e altamente letal, principalmente nas periferias; resultando no número de 564 mortos e 110 feridos segundo dados da pesquisa realizada pela Clínica de Direitos Humanos de Harvard e a organização Justiça Global (CLÍNICA DE DIREITOS HUMANOS \& JUSTIÇA GLOBAL, 2011). A maior parte dos homicídios de não-policiais não foi investigada e as denúncias sobre a prática de execuções sumárias e chacinas por membros das polícias não alcançou os objetivos estabelecidos por aqueles que conclamam por justiça e responsabilização dos culpados. A falta de investigações sérias e de responsabilização dos culpados, leva a crer que este tipo de ação atende a 
propósitos políticos específicos (BUENO, 2014).

\section{Considerações}

É uma responsabilidade científica e um desafio político importante tratar a segurança pública como objeto de estudo, tendo em vista a importância de produzir análises sobre os mecanismos de segurança e justiça no interior de um regime político democrático, de uma sociedade marcadamente desigual. A partir de um projeto de pesquisa mais amplo e tendo em vista as questões suscitadas nesta comunicação, é possível realizar algumas considerações sobre o atual modelo de gestão da segurança pública em São Paulo, a partir da observação das relações locais e dos fluxos de poder que mantém determinados padrões de conflitos violentos.

Um ponto importante trata especialmente das relações entre uso da força, letalidade e expansão do PCC, dos quais desdobram-se outros dois: as articulações entre a regulamentação estatal do crime e da punição, através da polícia e do sistema penitenciário; e as relações estabelecidas no interior das prisões e fora delas, na rede identificada como "mundo do crime". Este tópico refere-se, portanto, a uma própria análise conceitual sobre "controle social", recolocando as discussões contemporâneas sobre as formas através das quais se exercem práticas de vigilância e punição.

Interessante notar que as polícias, especialmente a Polícia Militar, apesar da prerrogativa legal de uso da força, recorre a métodos informais de ação para atingir seus objetivos. Ao mesmo tempo, o PCC, que ao longo de mais de 20 estruturou uma organização criminal complexa, portanto, ilegal, recorra a métodos formais e burocráticos de atuação.

Por informalidade entende-se o exercício de uma forma de controle social que embasada no modelo jurídico (a lei), configura-se como um dispositivo de segurança pautado por uma interpretação da realidade e de ação normativa, que não é correspondente aos códigos constitucionais de uso da força compatíveis com o estado democrático e com respeito aos Direitos Humanos. A norma suspende a lei, criando um estado de exceção permanente (AGAMBEN, 2004). A formalidade da ação de uma organização criminosa como o PCC, por outro lado, corresponde à uma interpretação 
do processo de estruturação e de ação da organização. A criação de estatutos, setores responsáveis por assistência jurídica, à família dos presos e aos negócios da facção, revelam uma complexa operação calcada em relações formais, hierárquicas e com protocolos definidos (DIAS \& MANSO, 2018).

Os impactos à vida social e à democracia ainda são imensuráveis. Mas é possível afirmar que está em desenvolvimento um processo mais amplo de disputas pelas redes criminais, e que certamente não podemos deslocar essas análises das interpretações sobre a ação estatal através dos sistemas de segurança pública e justiça criminal.

A atuação política da polícia e do PCC reporta a fluxos e relações de poder que envolvem a reprodução de um saber securitário, o controle punitivo dos ilegalismos e a própria eliminação dos “oponentes”. A norma (FOUCAULT, 2014) figura como regra nesses dispositivos de controle. Neste caso, a regulação social da violência pelo PCC remete à organização enquanto referência moral e instância balizadora de experiências locais através do controle de uma economia informal, da mediação dos conflitos e da definição de uma disciplina. Esta, ao contrário de remeter ao estrito cumprimento regras prescritivas, aproxima-se mais de uma dinâmica discursiva em que os irmãos (membros "batizados" na organização), colaboradores e residentes sob influência da ação do PCC e, portanto, sujeitos ao seu controle, pautam seu comportamento de acordo com o proceder, noção que remete ao conjunto ético e moral que define, no mundo do crime, o que é o certo (BIONDI, 2014; MARQUES, 2009).

É preciso avançar nos estudos sobre a militarização das forças policiais e sobre a formação e consolidação das facções criminais no Brasil. Os elevados índices de homicídios dolosos, os crescentes números de pessoas presas e a persistência da violência policial, são alguns dos indicadores que apontam para o aprofundamento do problema da "violência" na sociedade contemporânea

\section{Referências}

ADORNO, Sérgio. A criminalidade urbana violenta no Brasil: um recorte temático. $B I B$, Rio de Janeiro, n.35, p.3-24, 1993. 
. Monopólio Estatal da Violência na Sociedade Brasileira Contemporânea. In: MICELI, S. (org.) O que ler na Ciência Social Brasileira, v. IV. São Paulo: ANPOCS/Ed. Sumaré/CAPES, p.267-307, 2002.

AGAMBEN, Giorgio. Estado de exceção. Tradução Iraci D. Poleti. 2 $2^{\mathbf{a}}$ ed. São Paulo: Boitempo, 2004.

ALVAREZ, Marcos Cesar. Controle Social: notas em torno de uma noção polêmica. São Paulo em Perspectiva, São Paulo, v.18, n.1, p.168-176, 2004.

BIONDI, K. Etnografia no movimento: território, hierarquia e lei no PCC. 2014. 336 f. Tese (Doutorado em Ciências Humanas). Universidade Federal de São Carlos, São Carlos, 2014.

BUENO, Samira. Bandido bom é bandido morto: a opção ideológico-institucional da política de segurança pública na manutenção de padrões de atuação violentos da polícia militar paulista. 2014. 145f. Dissertação (Mestrado em Administração Pública e Governo). Escola de Administração de Empresas, FGV, São Paulo, 2014.

CALDEIRA, Tereza Pires do Rio. Cidade de muros: crime, segregação e cidadania em São Paulo. São Paulo: Edusp/34, 2001.

CLÍNICA DE DIREITOS HUMANOS; JUSTIÇA GLOBAL. São Paulo sob achaque: corrupção, crime organizado e violência institucional em maio de 2006. São Paulo, maio de 2001. 245p.

DIAS, Camila Caldeira Nunes. Da pulverização ao monopólio da violência: expansão e consolidação do Primeiro Comando da Capital (PCC) no sistema carcerário paulista. 2011. 386f. Tese (Doutorado em Sociologia). Faculdade de Filosofia, Letras e Ciências Humanas, Universidade de São Paulo, São Paulo, 2011.

DIAS, Camila Caldeira Nunes; MANSO, Bruno Paes. A Guerra. A ascensão do PCC e o mundo do crime no Brasil. São Paulo: Todavia, $1^{a}$ ed., 2018.

DURKHEIM, Émile. Da divisão do trabalho social. São Paulo: Martins Fontes, 2010.

FELTRAN, G. de S. O legítimo em disputa: as fronteiras do "mundo do crime" nas periferias de São Paulo. Dilemas - Revista de Estudos de Conflito e Controle Social, Rio de Janeiro, v.1, n.1, p.93-126, 2008.

Crime e castigo na cidade: os repertórios de justiça e a questão dos homicídios nas periferias de São Paulo. Cadernos CHR, Salvador, v.23, n.58, jan/abr, 2010.

FÓRUM BRASILEIRO DE SEGURANÇA PÚBLICA. Anuário do Fórum brasileiro de Segurança Pública. Relatórios de 2011-2017. 
FOUCAULT, Michel. História da sexualidade I: a vontade de saber. Tradução Maria T. C. Albuquerque e J. A. Guilhon Albuquerque. 16르 ed. Rio de Janeiro: Edição Graal, 1988.

Em Defesa da Sociedade: curso no Collège de France (1975- 1976). Tradução Maria Ermantina Galvão, 2ª ed., São Paulo: Martins Fontes, 2010.

. Vigiar e Punir: nascimento da prisão. Tradução de Raquel Ramalhete. 42 ed. Petrópolis, Rio de Janeiro: Vozes, 2014.

GODOI, Rafael. Fluxos em cadeia: as prisões em São Paulo na virada dos tempos. 2015. 243f. Tese (Doutorado em Sociologia). Faculdade de Filosofia, Letras e Ciências Humanas, Universidade de São Paulo, São Paulo, 2015.

KANT DE LIMA, R.; MISSE, M.; MIRANDA, Ana Paula M. Violência, Criminalidade, Segurança Pública e Justiça Criminal no Brasil: uma bibliografia. BIB - Revista Brasileira de Informação Bibliográfica em Ciências Sociais, Rio de Janeiro, n. 50, p.45-123, 2000

MARQUES, Adalton. Crime, proceder, convívio-seguro. Um experimento antropológico a partir da relação entre ladrões. Dissertação (Mestrado em Antropologia Social). Faculdade de Filosofia, Letras e Ciências Humanas, Universidade de São Paulo, São Paulo, 2009.

NEME, Cristina. A instituição militar na ordem democrática: o caso da Polícia Militar do Estado de São Paulo. São Paulo. 1999. 107f. Dissertação (Mestrado em Ciência Política). Faculdade de Filosofia, Letras e Ciências Humanas, Universidade de São Paulo, São Paulo, 1999.

SINHORETTO, Jacqueline; SILVESTRE, Giane; SCHLITTLER, Maria Carolina. Desigualdade Racial e Segurança Pública em São Paulo. Sumário Executivo. São Carlos: abril, 2004.

SOUZA, Luís Antônio Francisco de. Dispositivo militarizado da segurança pública. Tendências recentes e problemas no Brasil. Revista Sociedade e Estado, Brasília, v.3o, n.1, p. 207-223, abr, 2015.

TELLES, Vera da Silva. As cidades nas fronteiras do legal e do ilegal. Belo Horizonte: Argumentum, 2010.

VASCONCELOS, Francisco T. Rocha. As Ciências Sociais brasileiras e a formação do "campo da segurança pública". Revista Brasileira de Sociologia, v.5, n.9, jan/abr. 2017. p.33-58.

WEBER, Max. A política como vocação. In: . Ciência e Política. São Paulo: Cultrix, 1985 . 